\title{
CHRONIC OBSTRUCTIVE PULMONARY DISEASE
}

\section{Tiotropium for stable chronic obstructive pulmonary disease: a meta-analysis}

R G Barr, J Bourbeau, C A Camargo, F S F Ram

See end of article for authors' affiliations

Correspondence to: Dr R G Barr, Division of General Medicine, PH-9 East Room 105, Columbia University Medical Centre, 630 West 168th Street,

New York, NY 10032,

USA; rgb9@ columbia.edu

Received 29 March 2006

Accepted 16 June 2006

Published Online First

14 July 2006

Background: A systematic review was undertaken to evaluate the efficacy of tiotropium, a long acting anticholinergic drug, on clinical events, symptom scales, pulmonary function, and adverse events in stable chronic obstructive pulmonary disease (COPD).

Methods: A systematic search was made of the Cochrane trials database, MEDLINE, EMBASE, CINAHL, and a hand search of 20 respiratory journals. Missing data were obtained from authors and the manufacturer. Randomised controlled trials of $\geqslant 12$ weeks' duration comparing tiotropium with placebo, ipratropium bromide, or long acting $\beta_{2}$ agonists (LABA) were reviewed. Studies were pooled to yield odds ratios (OR) or weighted mean differences with $95 \%$ confidence intervals $(\mathrm{Cl})$.

Results: Nine trials (8002 patients) met the inclusion criteria. Tiotropium reduced the odds of a COPD exacerbation (OR $0.73 ; 95 \% \mathrm{Cl} 0.66$ to 0.81 ) and related hospitalisation (OR $0.68 ; 95 \% \mathrm{Cl} 0.54$ to 0.84 ) but not pulmonary (OR $0.50 ; 95 \% \mathrm{Cl} 0.19$ to 1.29 ) or all-cause (OR $0.96 ; 95 \% \mathrm{Cl} 0.63$ to 1.47 ) mortality compared with placebo and ipratropium. Reductions in exacerbations and hospitalisations compared with LABA were not statistically significant. Similar patterns were evident for quality of life and symptom scales. Tiotropium yielded greater increases in forced expiratory volume in 1 second $\left(F E V_{1}\right)$ and forced vital capacity (FVC) from baseline to 6-12 months than did placebo, ipratropium, and LABA. Decline in FEV 1 over 1 year was $30 \mathrm{ml}$ (95\% Cl 7 to 53) slower with tiotropium than with placebo and ipratropium (data were not available for $L A B A)$. Reports of dry mouth and urinary tract infections were increased with tiotropium. Conclusions: Tiotropium reduced COPD exacerbations and related hospitalisations, improved quality of life and symptoms, and may have slowed the decline in $\mathrm{FEV}_{1}$. Long term trials are warranted to evaluate the effects of tiotropium on decline in $\mathrm{FEV}_{1}$ and to clarify its role compared with LABA.

$\mathrm{C}$ hronic obstructive pulmonary disease (COPD) is currently the fourth or fifth leading cause of death in the most developed countries, and is projected to be the third cause of death worldwide by $2020 .{ }^{1}$ Despite this burden, few pharmacological treatments for COPD have been proved to reduce clinical events, and none has been shown definitively to slow decline in forced expiratory volume in 1 second $\left(\mathrm{FEV}_{1}\right)$.

Tiotropium has a quaternary ammonium structure related to that of ipratropium bromide. It dissociates slowly from $M_{1}$ and $\mathrm{M}_{3}$ receptors but rapidly from $\mathrm{M}_{2}$ receptors, ${ }^{2}$ which allows once daily dosing and has theoretical advantages since $\mathrm{M}_{2}$ receptors are feedback inhibitory receptors. ${ }^{3}{ }^{4}$

A number of randomised clinical trials suggest that tiotropium might reduce clinical event rates and improve lung function, but these trials have been of borderline statistical power. We therefore undertook a meta-analysis of available randomised trials to evaluate the efficacy of tiotropium on clinical events, health related quality of life, symptoms, pulmonary function, and adverse events compared with placebo, ipratropium bromide, and long acting $\beta_{2}$ agonists (LABA). An earlier version of this meta-analysis was published electronically in the Cochrane Library. ${ }^{5}$

\section{METHODS}

\section{Data sources}

The Cochrane Airways Review Group Specialised Register of COPD trials is a compilation of references to reports of controlled clinical trials assembled from systematic searches of the Cochrane Central Register of Controlled Trials (CENTRAL), MEDLINE, EMBASE and CINAHL, and supplemented by hand searching of leading respiratory journals and conference abstracts. It is not limited by language of publication. The Register was searched using the following terms: tiotropium OR "Ba 679 BR" OR Spiriva OR oxitropium. In addition, a search of LILACS and CENTRAL was performed. Searches were current as of May 2006.

Reference lists of all primary studies and review articles were reviewed for additional references. Authors of identified randomised trials were asked about published and unpublished studies. The manufacturer of tiotropium (Boehringer Ingelheim) was contacted regarding overlap between studies, unpublished studies, and supplemental data. Additional data were obtained from the Food and Drug Administration website. ${ }^{6}$

\section{Study selection}

The following criteria were used to select randomised controlled trials for inclusion in the meta-analysis:

- Target population: stable COPD consistent with American Thoracic Society (ATS)/European Respiratory Society (ERS) criteria, ${ }^{7}$ without evidence of an exacerbation for 1 month prior to study entry;

- Intervention: randomised clinical trials comparing tiotropium with placebo, ipratropium bromide, or LABA;

- Methodological criteria: studies that followed patients for 12 weeks or more after randomisation.

Two reviewers independently identified trials that appeared potentially relevant from titles and abstracts.

Abbreviations: COPD, chronic obstructive pulmonary disease; $\mathrm{FEV}_{1}$, forced expiratory volume in 1 second; FVC, forced vital capacity; LABA, long acting $\beta_{2}$ agonist; SGRQ, St George's Respiratory Questionnaire; TDI, Transitional Dyspnoea Index 
Using the abstract or the full text of each study, as necessary, two reviewers independently decided if trials fulfilled inclusion criteria for the review. Differences were resolved by discussion.

\section{Data extraction and assessment of methodological quality}

Two reviewers independently extracted data. Intention-totreat results were used whenever available. Primary clinical outcomes were COPD exacerbations, related hospitalisations, and all-cause mortality. Secondary outcomes included disease specific mortality, health related quality of life scales (St George's Respiratory Questionnaire [SGRQ] ${ }^{8}$ ), symptom scores (Transitional Dyspnea Index [TDI], a multidimensional measure of breathlessness ${ }^{9}$ ), change in trough $\mathrm{FEV}_{1}$ and forced ventilatory capacity (FVC) from baseline and from steady state 8-15 days after randomisation, and adverse events (dry mouth, constipation, urinary infection and obstruction, chest pain, myocardial infarction, arrhythmias and congestive heart failure). Methodological quality was assessed using the Cochrane approach and Jadad criteria. ${ }^{10}$

\section{Statistical analysis}

Trials were combined using RevMan (Version 4.2.8). Fixed effect odds ratios (OR) for dichotomous variables and weighted mean differences (WMD) for continuous variables with 95\% confidence intervals (CI) were calculated for individual trials. Trials were pooled using fixed effect OR or WMD as appropriate. Heterogeneity was tested using the Breslow-Day test with a $\mathrm{p}$ value $<0.1$ considered statistically significant. A random effects model was used if heterogeneity was found. Weighted averages of cumulative incidences in the control

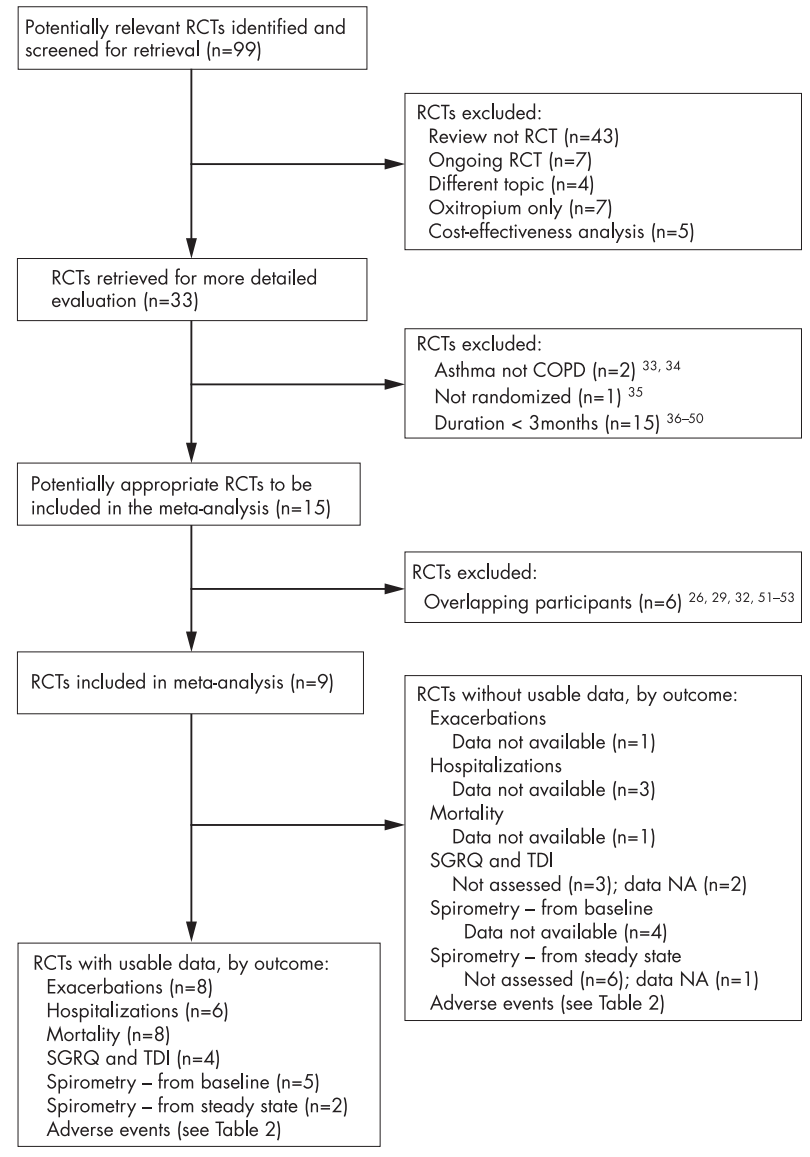

Figure 1 QUOROM flow diagram. groups were calculated across all trials and for trials of 12 months' duration. Numbers needed to treat (NNT) were calculated from the pooled OR, 95\% CI, and cumulative incidences in the control groups of the 12 month trials. ${ }^{11}$

For each outcome, trials were pooled within categories of control group (placebo, ipratropium, or LABA). Since an earlier large randomised clinical trial showed that ipratropium does not reduce clinical events or slow the decline in $\mathrm{FEV}_{1}$ relative to placebo, ${ }^{12}{ }^{13}$ summary estimates were calculated comparing tiotropium with placebo or ipratropium for these end points when there was statistical homogeneity across categories of control group. Adverse events were combined across all categories of control group when there was statistical homogeneity.

Publication bias was examined in funnel plots and tested with a modified Macaskill's test. ${ }^{14}$ The effects of tiotropium were examined across predefined subgroups by disease severity and concurrent LABA use.

\section{RESULTS}

Ninety nine articles were identified, of which 33 possibly fulfilled the inclusion criteria and 15 met the inclusion criteria (fig 1). Three of these articles reported the combined results of pairs of previously published and unpublished trials, and three others were secondary reports with overlapping participants. The net number of included trials was nine (8002 randomised patients). Table 1 shows the characteristics of the nine included trials.

Six of the included trials compared tiotropium with placebo, one compared tiotropium with ipratropium, ${ }^{15}$ one compared tiotropium with a LABA (salmeterol), ${ }^{16}$ and one compared tiotropium with placebo and with salmeterol. ${ }^{17}$ Six trials scored four out of five for methodological quality, two scored five out of five, ${ }^{15}{ }^{18}$ and one scored three out of five. ${ }^{19}$ Allocation concealment was described in only one trial. ${ }^{15}$ The protocols were extremely similar. All trials enrolled patients regardless of response to bronchodilators but excluded patients with a prior history of asthma; all but one ${ }^{18}$ excluded patients with a history of atopy or allergic rhinitis; and six excluded patients with a raised eosinophil count. All trials prohibited the use of non-study ipratropium and all but one ${ }^{18}$ prohibited the use of non-study LABA.

The weighted mean duration of the trials was 7.0 months (range 3-12). The severity of COPD was generally moderate to severe (ERS/ATS stage III-IV; range stage II-V); $38-80 \%$ of patients were taking ipratropium at enrolment, $32-50 \%$ were taking LABA, and $42-80 \%$ were taking inhaled corticosteroids.

\section{Clinical events \\ COPD exacerbations}

The cumulative incidence of COPD exacerbations among controls was $35 \%$ over the mean duration ( 7.0 months) of all trials, and $52 \%$ in the 1 year trials. Tiotropium reduced COPD exacerbations compared with placebo and compared with ipratropium (fig 2A). The cumulative incidence of exacerbations was lower with tiotropium than with salmeterol, but this difference was smaller and not statistically significant. The treatment effect of tiotropium was statistically homogeneous across the control groups $(p=0.77)$ and the summary OR for tiotropium compared with placebo or ipratropium was 0.73 (95\% CI 0.66 to 0.81 ). The corresponding NNT for tiotropium to prevent one exacerbation per year was $13(95 \%$ CI 10 to 21$)$.

\section{Hospitalisations for COPD exacerbations}

The cumulative incidence of exacerbation related hospitalisations among controls was 7\% over the duration of all trials, and $9 \%$ in the 1 year trials. Tiotropium reduced the risk of hospitalisation for COPD exacerbations compared with placebo 


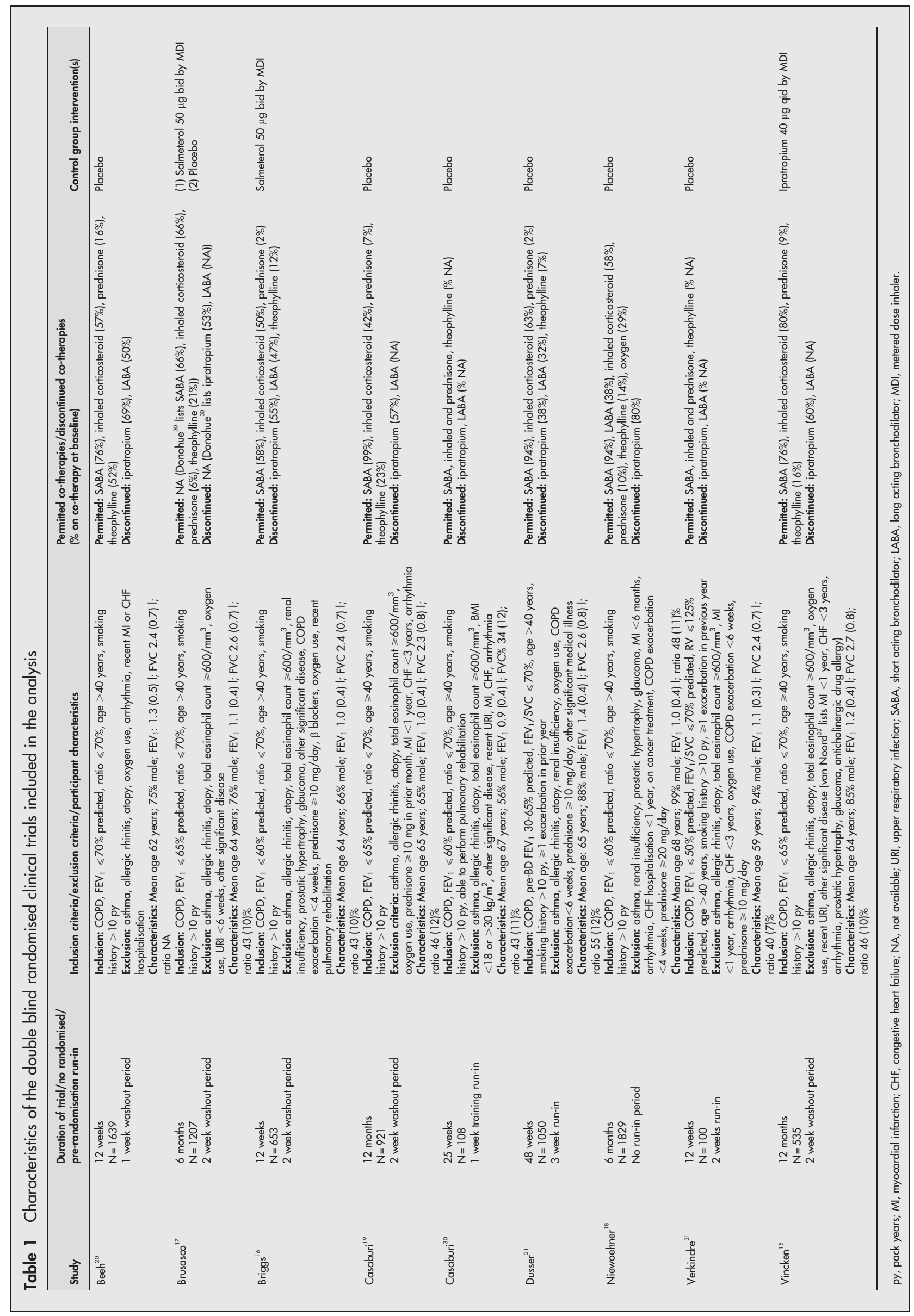




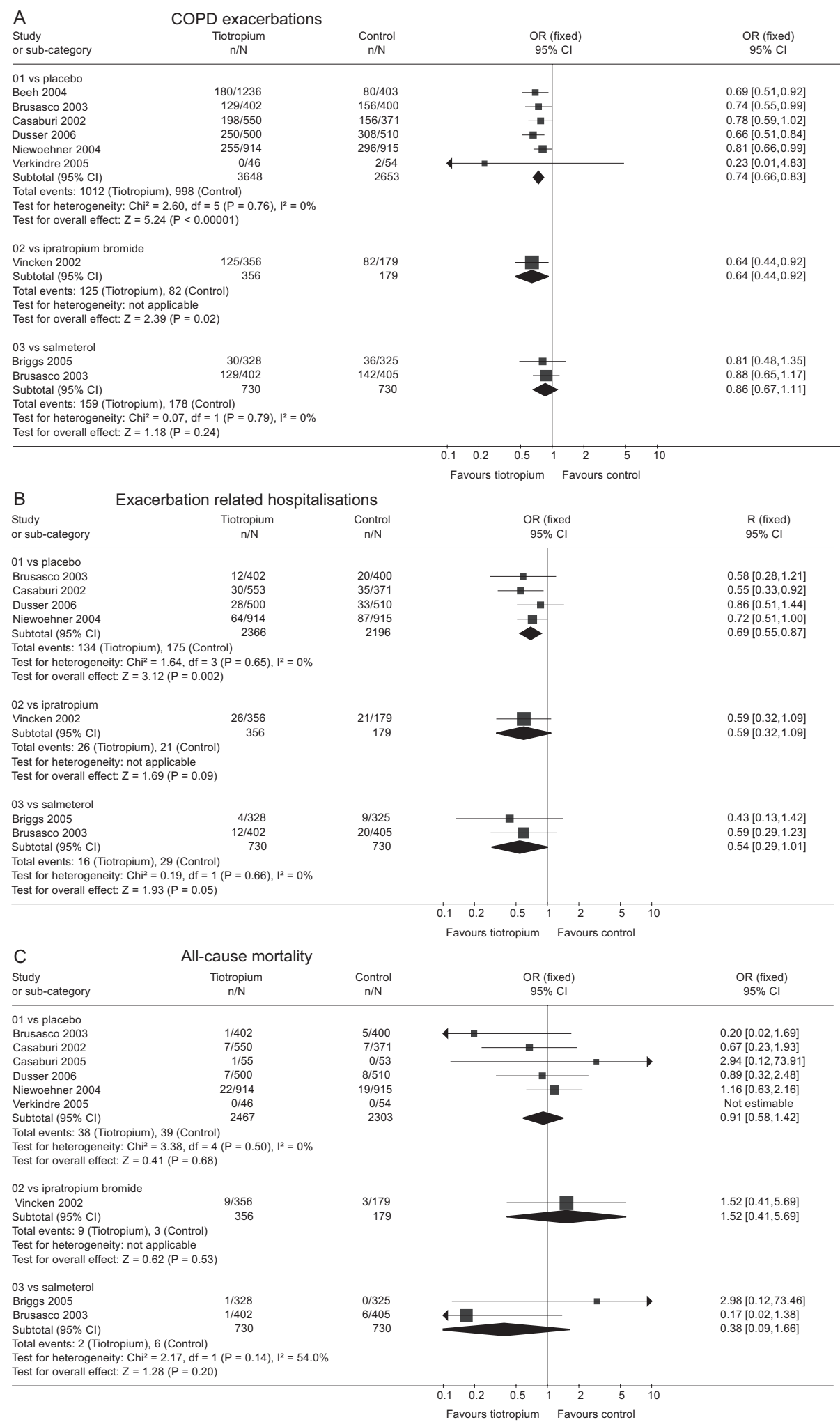

Figure 2 Summary effects of tiotropium on (A) COPD exacerbations, (B) hospitalisations, and (C) all-cause mortality.

(fig 2B). Similar reductions in hospitalisations were observed compared with ipratropium and compared with salmeterol, but neither of these differences was statistically significant. The treatment effect of tiotropium was statistically homogeneous across the control groups $(\mathrm{p}=0.76)$ and the summary estimate for tiotropium compared with placebo or ipratropium was OR 0.68 (95\% CI 0.54 to 0.84 ). The corresponding NNT for tiotropium to prevent one exacerbation related hospitalisation per year was 38 (95\% CI 26 to 76 ).

\section{Mortality}

Cumulative all-cause mortality among controls was 1.5\% over the duration of all trials and $1.7 \%$ in the 1 year trials. There were no statistically significant differences in all-cause 


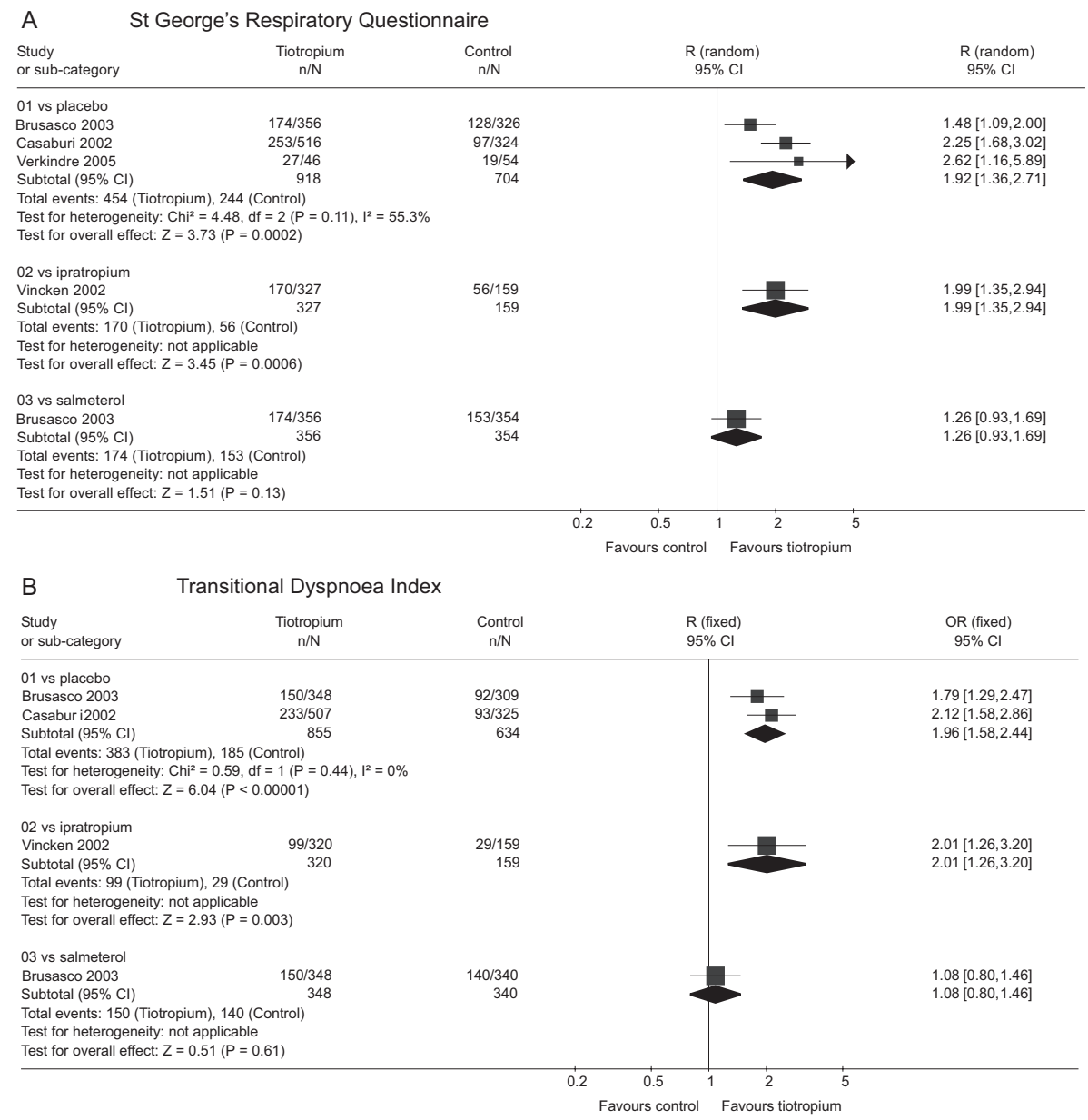

Figure 3 Summary effects of tiotropium on clinically significant changes in (A) St George's Respiratory Questionnaire and (B) Transitional Dyspnoea Index.

mortality between tiotropium and placebo, ipratropium, or salmeterol (fig 2C). The trials were statistically homogeneous across the control groups $(p=0.57)$ and the summary estimate for tiotropium compared with placebo or ipratropium was not significant (OR 0.96; 95\% CI 0.63 to 1.47 ).

Mortality from pulmonary causes was non-significantly lower with tiotropium compared with placebo or ipratropium (OR 0.50; 95\% CI 0.19 to 1.29; fig S1 available online only at http://www.thoraxjnl.com/supplemental). Heterogeneity was not evident. There were no statistically significant differences for cardiovascular mortality (OR 1.17; 95\% CI 0.54 to 2.51 ), cancer mortality $(0.77 ; 95 \%$ CI 0.28 to 2.12$)$, and mortality from other causes (OR 2.77; 95\% CI 0.81 to 9.45 ).

\section{Health related quality of life and symptom scales St George's Respiratory Questionnaire (SGRQ)}

The mean change in SGRQ over the course of the trials was larger with tiotropium than with placebo (WMD $-3.3 ; 95 \%$ CI -4.6 to -2.0 ) or with ipratropium (WMD -3.3 ; $95 \%$ CI -5.6 to -1.0$)$. A smaller and non-significant difference was observed compared with salmeterol (WMD - 1.4; 95\% CI -3.2 to 0.4 ). The trials were statistically homogeneous across the control groups $(p=0.31)$ and the summary estimate for tiotropium compared with placebo or ipratropium was an improvement of WMD -3.3 (95\% CI -4.7 to -2.2 ).

Similar results were observed for the proportion with a clinically significant change in SGRQ (fig 3A), although there was evidence of heterogeneity across the control groups $(\mathrm{p}=0.04)$.
Transitional Dyspnoea Index (TDI)

Data on mean change in TDI was inadequate for metaanalysis. The results for the proportion with a clinically significant change in TDI (fig 3B) were similar to those for SGRQ. There was evidence of heterogeneity across the control groups $(\mathrm{p}=0.07)$.

\section{Spirometric indices}

Change in $\mathrm{FEV}_{1}$ and FVC from baseline

The mean improvement in trough $\mathrm{FEV}_{1}$ from baseline to the end of the trials was greater with tiotropium than with placebo or ipratropium (fig 4A). A smaller but statistically significant difference was observed compared with salmeterol. There was evidence of statistical heterogeneity across the control groups $(\mathrm{p}<0.0001)$ which arose from the smaller mean difference compared with salmeterol. Similar results were seen for change in trough FVC from baseline (fig 4B).

\section{Change in $\mathrm{FEV}_{1}$ and FVC from steady state}

The mean decline in trough $\mathrm{FEV}_{1}$ from steady state was slower with tiotropium than with placebo (fig 5A). The treatment effect of tiotropium was similar to that of ipratropium, although the latter result was not statistically significant. The trials were statistically homogeneous across the control groups $(\mathrm{p}>0.99)$ and the summary estimate showed a WMD of $30 \mathrm{ml}$ $\left(95 \%\right.$ CI 7 to $53 \mathrm{ml}$ ) slower decline in $\mathrm{FEV}_{1}$ for tiotropium compared with placebo or ipratropium.

Declines in trough FVC from steady state to the end of the two trials were heterogeneous $(p=0.08)$ and no statistically 


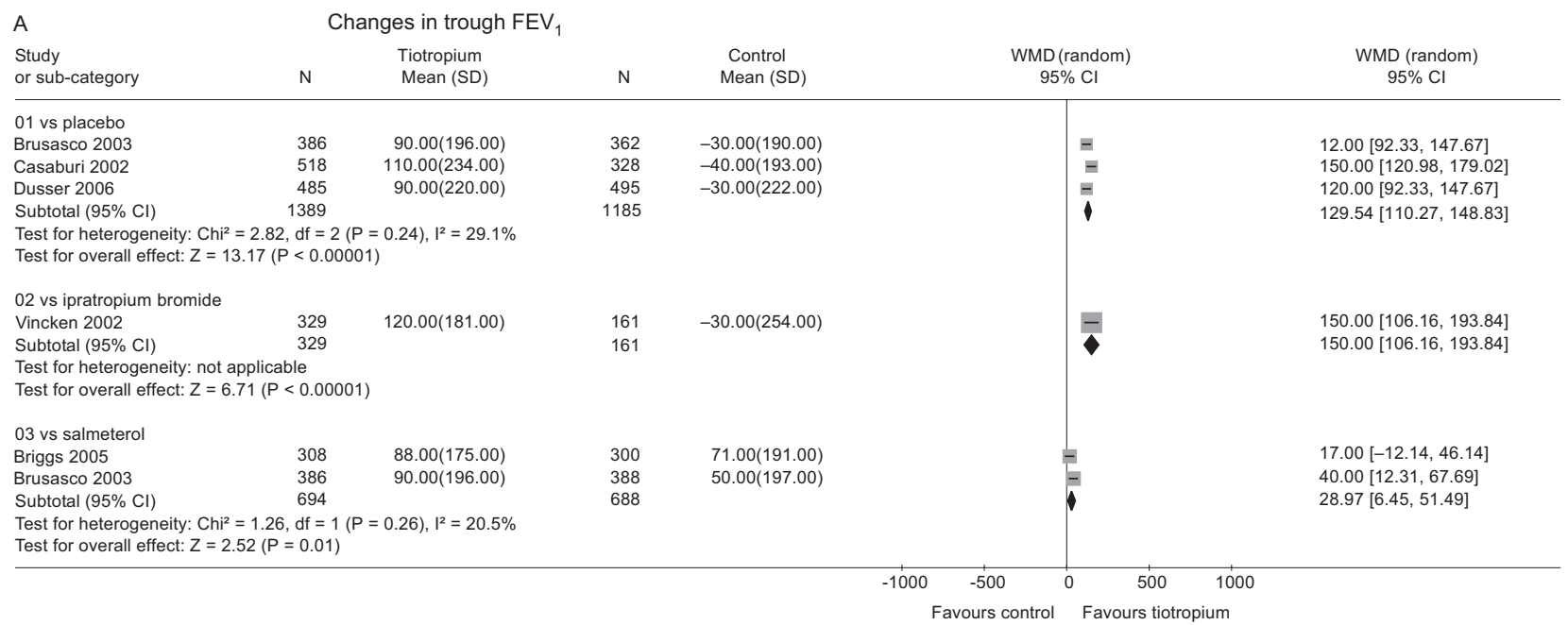

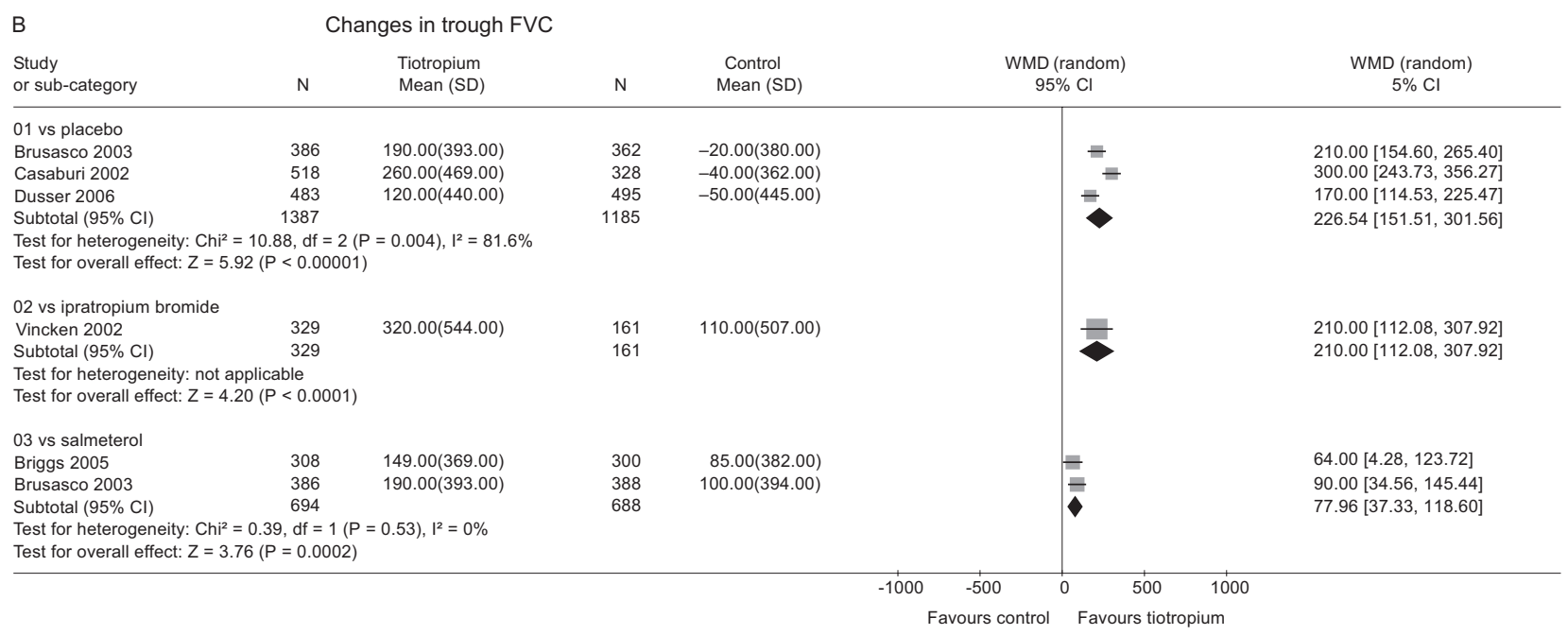

Figure 4 Summary effects of tiotropium on changes in (A) trough $\mathrm{FEV}_{1}$ and $(\mathrm{B})$ trough FVC from baseline before randomisation until end of trials.

significant differences were observed between tiotropium and either control group (fig 5B).

\section{Adverse events}

Available data on adverse events are summarised in table 2. Dry mouth was significantly increased with tiotropium compared with placebo, ipratropium and salmeterol, and urinary tract infections were significantly increased compared with placebo and ipratropium (data were not available for salmeterol). Consistent but not statistically significant increases were observed for systemic anticholinergic adverse events (constipation and urinary retention). Heterogeneity was evident for arrhythmias or atrial fibrillation overall and in comparison with placebo $(p=0.05)$. This heterogeneity resulted from one trial that reported atrial fibrillation results only. When this trial was excluded, heterogeneity was not evident $(p=0.71)$ and the frequency of arrhythmias was significantly higher with tiotropium than with placebo (OR 2.33; $95 \%$ CI 1.11 to 4.88 ).

\section{Subgroup and sensitivity analyses}

The trials were very similar with respect to disease severity and concurrent LABA use. The two trials with the highest baseline mean $\mathrm{FEV}_{1}{ }^{20}{ }^{21}$ had a statistically similar estimate for exacerbations as the pooled estimate and as a trial in which $29 \%$ of patients were on oxygen ${ }^{18}$ (fig 2).
The effect of tiotropium on exacerbations in the one trial ${ }^{18}$ that permitted concurrent use of LABA (OR 0.81; 95\% CI 0.66 to 0.99 ) was statistically similar to the others that withheld LABA (OR 0.70; 95\% CI 0.62 to 0.80 ).

Sensitivity analyses by quality weighting and random effects models yielded nearly identical results. Funnel plots for the primary end points showed no clear evidence of publication bias and the modified Macaskill test did not suggest publication bias for exacerbations $(\mathrm{p}=0.65)$.

\section{DISCUSSION}

This systemic review of the currently available randomised trials of tiotropium for stable COPD showed that tiotropium reduced COPD exacerbations and related hospitalisations compared with placebo or ipratropium. Increases in $\mathrm{FEV}_{1}$ and FVC from baseline were significantly larger with tiotropium than with placebo, ipratropium, and LABA. The decline in trough $\mathrm{FEV}_{1}$ from steady state was slower with tiotropium than with placebo or ipratropium, and pulmonary mortality was non-significantly lower with tiotropium.

The benefits observed with tiotropium for exacerbations and related hospitalisations were large and clinically important. Consistent with these findings, tiotropium has been shown to be cost effective although not cost saving compared with ipratropium in Europe. ${ }^{22}$ The magnitude of the reduction 


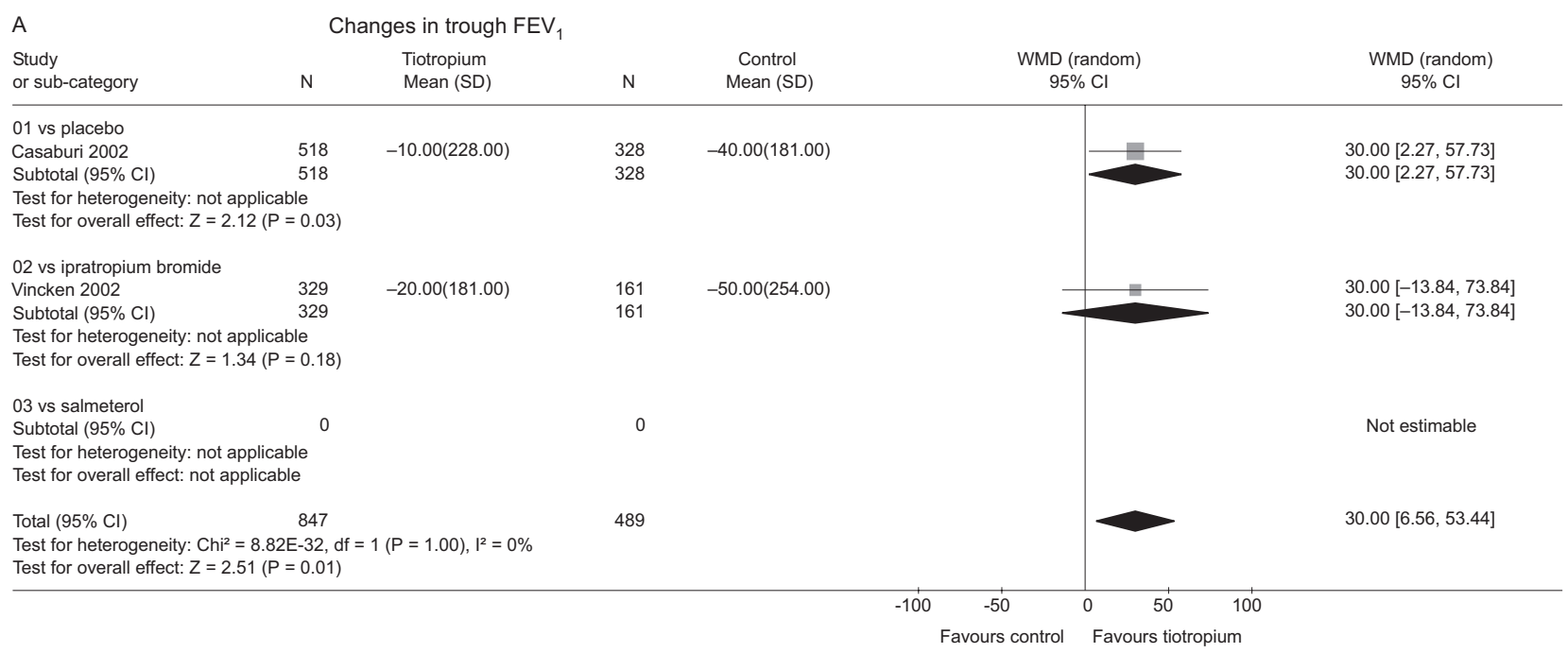

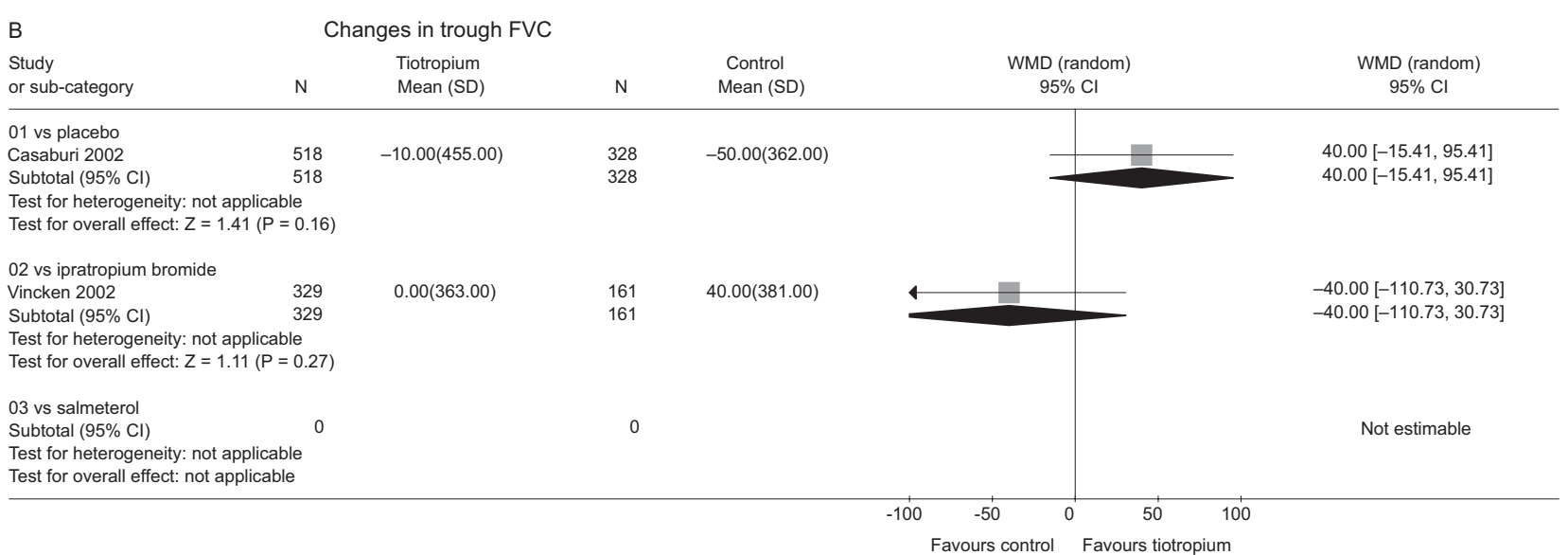

Figure 5 Summary effects of tiotropium on changes in (A) trough $F E V_{1}$ and $(B)$ trough $F V C$ from steady state 8 days after randomisation until end of trials (1 year).

in exacerbation related hospitalisations with tiotropium was similar in comparison with placebo, ipratropium and salmeterol, and was similar in large placebo controlled trials that did and did not permit use of LABA.

Changes in health related quality of life, symptom scales, and spirometric indices also appeared clinically significant. Compared with placebo and ipratropium, the mean change in the SGRQ across all participants was close to the clinically significant change in SGRQ of 4 units, and more participants on tiotropium achieved a clinically significant change in SQRQ and TDI compared with placebo and ipratropium. Improvements in spirometric indices from baseline were clinically significant compared with placebo and ipratropium at a threshold for FEV of $100 \mathrm{ml}^{23}$ but not at a threshold of $225 \mathrm{ml}^{24}$ Improvements in spirometric indices from baseline were statistically but not clinically significant compared with salmeterol.

The results of this systemic review are consistent with a previous review of treatments for $\mathrm{COPD}^{25}$ which reported on exacerbations and quality of life but which was limited by double counting of patients randomised to tiotropium. Our results correct and extend that review with more than twice the number of randomised patients and additional outcomes of hospitalisations, mortality, symptom scales, spirometric indices, and adverse events.

We found that the decline in trough $\mathrm{FEV}_{1}$ from steady state was slower with tiotropium than with placebo or ipratropium. This difference was large relative to the difference observed in a meta-analysis of inhaled corticosteroids in $\mathrm{COPD}^{26}$ and was consistent with a post hoc analysis of one of the tiotropium trials. ${ }^{27}$ However, this observation should be interpreted with caution as it might be due to (1) incomplete attainment of steady state of tiotropium at 8 days; (2) chance, given that multiple spirometric indices were measured and that the duration of the relevant trials was only 1 year; and (3) bias, given that most but possibly not all trial results for this measure were available for meta-analysis. Larger longer term trials are necessary to assess the validity of this result, which would be of major clinical relevance if replicated.

Mortality from pulmonary causes was non-significantly lower among those randomised to tiotropium compared with placebo or ipratropium. This finding suggests that observed benefits on exacerbations and hospitalisations might translate into reductions in pulmonary mortality, but requires evaluation in long term randomised trials designed specifically to examine pulmonary mortality. Estimates for disease-specific mortality can be subject to more biases than all-cause mortality, and we note that all-cause mortality did not differ appreciably between tiotropium and placebo.

The trials included in this review were of good quality and used almost identical designs with regard to inclusion and exclusion criteria. The clinical homogeneity of the trials resulted in statistical homogeneity for most outcome measures across the trials. We calculated summary estimates of the effects of tiotropium compared with placebo and ipratropium. Heterogeneity would be introduced if ipratropium had an effect on the relevant outcomes, but ipratropium has been shown not 
Table 2 Adverse events with tiotropium compared with placebo, ipratropium, and salmeterol, with summary estimates across all available data

\begin{tabular}{|c|c|c|c|c|c|}
\hline & Tiotropium cor & & & & \\
\hline & Placebo & Ipratropium & Salmeterol & heterogeneity & Summary estimate \\
\hline Dry mouth & & & & & \\
\hline Trials & 4 & 1 & 2 & 0.24 & 7 \\
\hline Participants & 2835 & 535 & 1460 & & 4830 \\
\hline Odds ratio & 4.6 & 2.1 & 4.7 & & 3.9 \\
\hline & & & & & \\
\hline Constipation & & & & & \\
\hline Trials & 2 & 1 & 0 & 0.41 & 3 \\
\hline Participants & 1931 & 535 & & & 2466 \\
\hline Odds ratio & 2.2 & 0.5 & & & 1.7 \\
\hline (95\% Cl) & (0.95 to 4.8 ) & (0.1 to 3.6$)$ & & & (0.8 to 3.7$)$ \\
\hline Urinary retentio & & & & & \\
\hline Trials & 3 & 0 & 1 & 0.85 & 4 \\
\hline Participants & 2733 & & & & 3540 \\
\hline Odds ratio & 2.5 & & 3.0 & & 2.6 \\
\hline (95\% Cl) & (0.5 to 14$)$ & & (0.1 to 75$)$ & & (0.6 to 12$)$ \\
\hline Urinary tract in & & & & & \\
\hline Trials & 3 & 1 & 0 & 0.91 & 4 \\
\hline Participants & 2733 & & & & 3268 \\
\hline Odds ratio & 1.6 & 1.8 & & & 1.6 \\
\hline$(95 \% \mathrm{Cl})$ & (0.97 to 2.6 ) & (0.6 to 5.5$)$ & & & (1.03 to 2.6 ) \\
\hline Chest pain & & & & & \\
\hline Trials & 3 & 1 & 1 & 0.09 & - \\
\hline Participants & 2733 & 535 & 807 & & \\
\hline Odds ratio & 0.9 & 2.5 & 1.2 & & \\
\hline (95\% Cl) & $(0.4$ to 2.0$)$ & (0.8 to 7.4 ) & (0.6 to 2.4 ) & & \\
\hline Myocardial info & & & & & \\
\hline Trials & 3 & 1 & 0 & 0.77 & 4 \\
\hline Participants & 2733 & 535 & & & 3268 \\
\hline Odds ratio & 1.0 & 1.5 & & & 1.1 \\
\hline$(95 \% \mathrm{Cl})$ & $(0.2$ to 3.9$)$ & (0.2 to 15$)$ & & & (0.3 to 3.6$)$ \\
\hline Arrhythmia or & & & & & \\
\hline Trials & 4 & 1 & 0 & 0.05 & - \\
\hline Participants & 4561 & 535 & & & \\
\hline Odds ratio & 1.4 & 0.8 & & & \\
\hline (95\% Cl) & (0.4 to 5.7 ) & (0.3 to 1.8 ) & & & \\
\hline Congestive hea & & & & & \\
\hline Trials & 3 & 1 & 0 & 0.86 & 4 \\
\hline Participants & 2837 & 535 & & & 3372 \\
\hline Odds ratio & 0.8 & 0.5 & & & 0.8 \\
\hline$(95 \% \mathrm{Cl})$ & (0.4 to 1.6$)$ & (0.1 to 8.1$)$ & & & (0.4 to 1.5$)$ \\
\hline
\end{tabular}

to alter the long term decline in $\mathrm{FEV}_{1},{ }^{13}$ hospitalisations or survival $^{12}$ compared with placebo. LABA, on the other hand, may reduce exacerbations compared with placebo. ${ }^{25} 28$

Potential limitations of meta-analyses include double counting of patients from overlapping publications, publication bias, reporting bias, and selection bias from differential inclusion of available trials. We avoided double counting by discussing trial overlap with the primary authors and the manufacturer of tiotropium, and evaluated for publication bias with funnel plots and statistical tests. Selective reporting of secondary end points and of non-intention to treat reports in published manuscripts may bias results; we minimised this bias by obtaining supplemental data for five of the nine included studies, although complete intention to treat analyses were missing for most studies due to missing data. We avoided selection bias by pre-specified inclusion and exclusion criteria, a systematic search, and independent evaluation of trial inclusion by two reviewers.

In conclusion, tiotropium reduced COPD exacerbations and exacerbation related hospitalisations compared with placebo or ipratropium. It also improved health related quality of life and symptom scores and can be recommended for the treatment of stable COPD. The results of this systematic review suggest that tiotropium may slow the decline in $\mathrm{FEV}_{1}$, although this finding requires confirmation in additional long term randomised clinical trials.

\section{ACKNOWLEDGEMENTS}

The authors thank Maria Martinez-Torres for assistance with manuscript preparation and various individuals at Boehringer-Ingelheim who helped provide unpublished data to strengthen this systematic review. The assistance of Phillippa Poole (Cochrane Airways Review Group co-editor) was greatly appreciated.

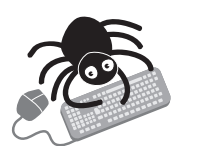

Figure S1 showing mortality from pulmonary causes, cardiovascular causes, cancer and other causes is available online at http://www.thoraxjnl.com/ supplemental.

\section{Authors' affiliations}

R G Barr, Irving Assistant Professor of Medicine and Epidemiology, Columbia University Medical Centre, New York, NY, USA

J Bourbeau, Associate Professor of Medicine, McGill University Health Centre, Montreal, Quebec, Canada 
C A Camargo, Associate Professor of Medicine, Massachusetts General Hospital, Harvard Medical School, Boston, MA, USA

F S F Ram, Senior Lecturer in Respiratory Medicine and Clinical Pharmacology, School of Health Sciences, Massey University, Auckland, New Zealand

Funding: Robert Wood Johnson Generalist Physician Faculty Scholar Award and National Institutes of Health (USA) HL075476, HL077612, HL063841.

Competing interests: Dr Barr: none. Dr Bourbeau has received honoraria for CME, membership on advisory boards and financial support from government agencies, contract and investigator initiated research studies for a number of companies including Altana, Astra Zeneca, Bayer, Boehringer-Ingelheim, GlaxoSmithKline, Novartis and Pfizer. Dr Camargo has received investigator initiated grants and consulting/ lecture honoraria from AstraZeneca, Boehringer-Ingelheim, GlaxoSmithKline, and Novartis. Dr Ram: none.

\section{REFERENCES}

1 Murray CJL, Lopez AD. Alternative projections of mortality and disability by cause 1990-2020: Global Burden of Disease Study. Lancet 1997;349:1498-504.

2 Haddad E, Mak J, Barnes P. Characterization of 3H Ba 679 BR, a slowly dissociation muscarinic antagonist, in human lung: radioligand binding and autoradiographic mapping. Mol Pharmacol 1994;45:899-907.

3 Disse B, Speck GA, Rominger KL, et al. Tiotropium (Spiriva): mechanistical considerations and clinical profile in obstructive lung disease. Life $\mathrm{Sci}$ 1999;64:457-64.

4 Barnes PJ. The pharmacological properties of tiotropium. Chest 2000;117(2 Suppl):63-6S.

5 Barr RG, Bourbeau J, Camargo CA Jr, et al. Inhaled tiotropium for stable chronic obstructive pulmonary disease. Cochrane Database of Systematic Reviews, 2005; Issue 2.

6 Food and Drug Administration, Pulmonary-Allergy Drugs Advisory Committee. Clinical briefing document. Integrated review of safety, NDA 21 395.Food and Drug Administration, 2002.

7 Celli BR, MacNee W. Standards for the diagnosis and treatment of patients with COPD: a summary of the ATS/ERS position paper. Eur Respir $J$ 2004;23:932-46.

8 Jones PW, Quirk FH, Baveystock CM, et al. A self-complete measure of health status for chronic airflow limitation. The St George's Respiratory Questionnaire. Am Rev Respir Dis 1992;145:1321-7.

9 Mahler DA, Weinberg DH, Wells CK, et al. The measurement of dyspnea: contents, interobserver agreement, and physiologic correlates of two new clinical indexes. Chest 1984;85:751-8.

10 Jadad AR, Moore RA, Carroll D, et al. Assessing the quality of reports of randomized clinical trials: is blinding necessary? Control Clin Trials 1996; 17:1-12

11 Cates C. Visual Rx. www.nntonline.net,, 2006.

12 Anthonisen NR, Connett JE, Enright PL, et al. Hospitalizations and mortality in the Lung Health Study. Am J Respir Crit Care Med 2002;166:333-9.

13 Anthonisen NR, Connett JE, Kiley JP, et al. Effects of smoking intervention and the use of an inhaled anticholinergic bronchodilator on the rate of decline of $\mathrm{FEV}_{1}$. The Lung Health Study. JAMA 1994;272:1497-505.

14 Macaskill P, Walter SD, Irwig L. A comparison of methods to detect publication bias in meta-analysis. Stat Med 2001;20:641-54.

15 Vincken W, van Noord JA, Greefhorst AP, et al. Dutch/Belgium Tiotropium Study Group. Improved health outcomes in patients with COPD during one year's treatment with tiotropium. Eur Respir J 2002;19:209-16.

16 Briggs DD Jr, Covelli H, Lapidus R, et al. Improved daytime spirometric efficacy of tiotropium compared with salmeterol in patients with COPD. Pulm Pharmacol Ther 2005; 18:397-404.

17 Brusasco V, Hodder R, Miravitlles $M$, et al. Health outcomes following treatment for six months with once daily tiotropium compared with twice daily salmeterol in patients with COPD. Thorax 2003;58:399-404.

18 Niewoehner D, Rice K, Cote C, et al. Prevention of exacerbations of chronic obstructive pulmonary disease with tiotropium, a once-daily inhaled anticholinergic bronchodilator. A randomized trial. Ann Intern Med 2005; 143:317-26.

19 Casaburi R, Mahler DA, Jones PW, et al. A long-term evaluation of once-daily inhaled tiotropium in chronic obstructive pulmonary disease. Eur Respir J 2002; 19:217-24

20 Beeh KM, Beier J, Buhl R, et al. Efficacy of tiotropium bromide (Spiriva) in patients with chronic obstructive pulmonary disease (COPD) of different severities (in German). Pneumologie 2006;60:341-6.

21 Dusser D, Bravo M-L, lacono P, on behalf of the MISTRAL Study Group. The effect of tiotropium on exacerbations and airflow in patients with COPD. Eur Respir J 2006;27:547-55.

22 Oostenbrink JB, Rutten-van Molken MP, Al MJ, et al. One-year costeffectiveness of tiotropium versus ipratropium to treat chronic obstructive pulmonary disease. Eur Respir J 2004;23:241-9.

23 Redelmeier DA, Goldstein RS, Min ST, et al. Spirometry and dyspnea in patients with COPD. When small differences mean little. Chest 1996;109:1163-8.
24 Herpel LB, Kanner RE, Lee SM, et al. Variability of spirometry in chronic obstructive pulmonary disease: results from two clinical trials. Am J Respir Crit Care Med 2006;173:1106-13.

25 Sin DD, McAlister FA, Anthonisen NR, et al. Contemporary management of chronic obstructive pulmonary disease: scientific review. JAMA 2003;290:2301-12.

26 Sutherland ER, Allmers H, Ayas NT, et al. Inhaled corticosteroids reduce the progression of airflow limitation in chronic obstructive pulmonary disease: a meta-analysis. Thorax 2003;58:937-41.

27 Anzueto A, Tashkin D, Menjoge S, et al. One-year analysis of longitudinal changes in spirometry in patients with COPD receiving tiotropium. Pulm Pharmacol Ther 2005;18:75-81.

28 Mahler DA, Donohue JF, Barbee RA, et al. Efficacy of salmeterol xinafoate in the treatment of COPD. Chest 1999;1 15:957-65.

29 Donohue JF, van Noord JA, Bateman ED, et al. A 6-month, placebocontrolled study comparing lung function and health status changes in COPD patients treated with tiotropium or salmeterol. Chest 2002;122:47-55.

30 Casaburi R, Kukafka D, Cooper CB, et al. Improvement in exercise tolerance with the combination of tiotropium and pulmonary rehabilitation in patients with COPD. Chest 2005;127:809-17.

31 Verkindre C, Bart F, Aquilaniu B, et al. The effect of tiotropium on hyperinflation and exercise capacity in chronic obstructive pulmonary disease. Respiration 2006;73:420-7.

32 van Noord JA, Bantje TA, Eland ME, et al. A randomised controlled comparison of tiotropium and ipratropium in the treatment of chronic obstructive pulmonary disease. The Dutch Tiotropium Study Group. Thorax 2000;55:289-94.

33 O'Connor BJ, Towse $\sqcup$, Barnes PJ. Prolonged effect of tiotropium bromide on methacholine-induced bronchoconstriction in asthma. Am J Respir Crit Care Med 1996; 154:876-80.

34 Terzano C, Petroianni A, Ricci A, et al. Early protective effects of tiotropium bromide in patients with airways hyperresponsiveness. Eur Rev Med Pharmacol Sci 2004;8:259-64.

35 Maesen FP, Smeets JJ, Costongs MA, et al. Ba $679 \mathrm{Br}$, a new long-acting antimuscarinic bronchodilator: a pilot dose-escalation study in COPD. Eur Respir J 1993;6:1031-6.

36 Maesen FPV, Smeets JJ, Sledsens TJ, et al. Tiotropium bromide, a new longacting anti-muscarinic bronchodilator: a pharmacodynamic study in patients with chronic obstructive pulmonary disease (COPD). Dutch Study Group. Eur Respir J 1995;8:1506-13.

37 Littner MR, llowite JS, Tashkin DP, et al. Long-acting bronchodilation with once-daily dosing of tiotropium (Spiriva) in stable chronic obstructive pulmonary disease. Am J Respir Crit Care Med 2000;161:1136-42.

38 van Noord JA, Smeets JJ, Custers FL, et al. Pharmacodynamic steady state of tiotropium in patients with chronic obstructive pulmonary disease. Eur Respir J 2002; 19:639-44.

39 Celli B, ZuWallack R, Wang S, et al. Improvement in resting inspiratory capacity and hyperinflation with tiotropium in COPD patients with increased static lung volumes. Chest 2003;124:1743-8.

40 Calverley PM, Lee A, Towse L, et al. Effect of tiotropium bromide on circadian variation in airflow limitation in chronic obstructive pulmonary disease. Thorax 2003;58:855-60.

41 Cazzola M, Di Marco F, Santus P, et al. The pharmacodynamic effects of single inhaled doses of formoterol, tiotropium and their combination in patients with COPD. Pulm Pharmacol Ther 2004;17:35-9.

42 Cazzola M, Centanni S, Santus P, et al. The functional impact of adding salmeterol and tiotropium in patients with stable COPD. Respir Med 2004;98:1214-21

43 O'Donnell DE, Fluge T, Gerken F, et al. Effects of tiotropium on lung hyperinflation, dyspnoea and exercise tolerance in COPD. Eur Respir J 2004;23:832-40.

44 Hasani A, Toms N, Agnew JE, et al. The effect of inhaled tiotropium bromide on lung mucociliary clearance in patients with COPD. Chest 2004; 125:1726-34.

45 McNicholas WT, Calverley PM, Lee A, et al. Long-acting inhaled anticholinergic therapy improves sleeping oxygen saturation in COPD. Eur Respir J 2004;23:825-31.

46 Cazzola M, Noschese P, Salzillo A, et al. Bronchodilator response to formoterol after regular tiotropium or to tiotropium after regular formoterol in COPD patients. Respir Med 2005;99:524-8.

47 Baloira Villar A, Vilarino Pombo C. [Bronchodilator efficacy of combined salmeterol and tiotropium in patients with chronic obstructive pulmonary disease]. Arch Bronconeumol 2005;41:130-4

48 Maltais F, Hamilton A, Marciniuk D, et al. Improvements in symptom-limited exercise performance over $8 \mathrm{~h}$ with once-daily tiotropium in patients with COPD. Chest 2005;128:1168-78.

$49 \mathrm{Kim}$ Sj, Kim MS, Lee SH, et al. A comparison of tiotropium $18 \mu \mathrm{g}$, once daily and ipratropium $40 \mu \mathrm{g}, 4$ times daily, in a double-blind, double-dummy, efficacy and safety study in adults with chronic obstructive pulmonary disease (Korean). Korean Tuberc Respir Dis 2005;58:498-506

50 van Noord JA, Aumann JL, Janssens E, et al. Comparison of tiotropium once daily, formoterol twice daily and both combined once daily in patients with COPD. Eur Respir J 2005;26:214-22.

51 Casaburi R, Briggs DD, Donohue JF, et al. The spirometric efficacy of oncedaily dosing with tiotropium in stable COPD: a 13-week multicenter trial. The US Tiotropium Study Group. Chest 2000;1 18:1294-302.

52 Donohue JF, Menjoge S, Kesten S. Tolerance to bronchodilating effects of salmeterol in COPD. Respir Med 2003;97:1014-20.

53 Tashkin D, Kesten S. Long-term treatment benefits with tiotropium in COPD patients with and without short-term bronchodilator responses. Chest 2003;123:1441-9. 
systematic sampling, but is avoided in trials with patients prospectively randomised and analysed on an intention-to-treat basis. We emphasise that we did not perform any stagebased subanalyses, but compared the whole CMLND population with the systematic sampling group.

The exclusions after randomisation clearly should not have occurred, but were adequately reported. In all, 25 patients had small-cell cancer or a non-malignant pathology, 48 had incomplete primary resection, 5 turned out to have metastatic deposits from other sites and 15 were excluded because of upstaging to IIIB or IV only. The exclusions were well matched, with 52 occurring in the CMLND group and 41 in the systematic sampling group. We therefore believe this had little effect on the overall analysis.

It should also be mentioned that in one of the trials, only patients with cTINO adenocarcinoma of $\leqslant 2 \mathrm{~cm}$ diameter were randomised. Mechanistically, the authors hypothesised that this is the group least likely to benefit from CMLND; however, their inclusion in the pooled analysis still resulted in a clear benefit in favour of CMLND. In fact, the pooled hazard ratio of 0.78 is superior to that of adjuvant chemotherapy meta-analyses ${ }^{4}$ that have created such enthusiasm in lung cancer circles of late. Therefore, we are concerned that as a result of this editorial, groups treating lung cancer may not demand from their surgeons that which they are demanding from their medical oncologists-an evidence-based improvement in survival with an adjuvant intervention.

We also await the results of the ACOSOG Z30 trial, ${ }^{5}$ which will address this question for patients in clinical stage I. This will also allow a pooled analysis of 1959 patients, which should be able to put this question to rest after 50 years of controversy. Until then, the level I evidence is that CMLND should be performed as part of the surgical treatment of patients with stage I-IIIA non-small-cell lung cancer.

Gavin M Wright

Correspondence to: G M Wright, St Vincent's Hospital, 55 Victoria Parade Fitzroy, Melbourne 3065, Victoria, Australia; gavin.wright@svhm.org.au

Competing interests: None declared.

\section{References}

1 Wright G, Manser RL, Byrnes G, et al. Surgery for non-small cell lung cancer: systematic review and meta-analysis of randomised controlled trials. Thorax 2006;61:597-603.
2 Holty J-EC, Gould MK. When in doubt should we cut it out? The role of surgery in non-small cell lung cancer. Thorax 2006;61:554-6.

3 Feinstein AR, Sosin DM, Wells CK. The Will Rogers phenomenon. Stage migration and new diagnostic techniques as a source of misleading statistics for survival in cancer. $N$ Engl $\mathrm{J}$ Med 1985:312:1604-8

4 Pignon JP, Tirbodet $\mathrm{H}$, Scagliotti GV, et al. Lung Adjuvant Cisplatin Evaluation: a pooled analysis of five randomised clinical trials including 4,584 patients. Proc Am Soc Clin Oncol 2006;24(Part 1): No 188, 7008.

5 Allen MS, Darling GE, Pechet $\Pi$, et al. Morbidity and mortality of major pulmonary resections in patients with early-stage lung cancer: initial results of the randomized, prospective ACOSOG Z0030 trial. Ann Thorac Surg 2006;81:1013-19.

\section{Authors' reply}

We thank Dr Wright for his comments, but respectfully disagree. Although it is certainly possible that complete mediastinal lymph node dissection (CMLD) might improve survival in non-small-cell lung cancer (NSCLC), all three of the studies performed to date were limited by stage migration and other biases. Although overall exclusions were matched, we do not know whether exclusions due to upstaging were necessarily matched between study arms. In fact, limited data from the studies suggest that they were not. In the study by $\mathrm{Wu}$ et al after post-randomisation exclusions, there were more patients with stage I (42\% v $24 \%$ ) and fewer with stage IIIa $(28 \% v 48 \%)$ in the lymph node sampling group than in the CMLD group. Furthermore, the authors of one of the other three included studies concluded that stage migration might have resulted in an observed survival benefit for patients undergoing CMLD, ${ }^{2}$ and a previous systematic review on CMLD in NSCLC also concluded that stage migration existed for two of the three included studies. $^{3}$

In addition, there are other limitations. For example, because the study by Sugi et $\mathrm{al}^{4}$ included only patients with peripheral NSCLC $<2 \mathrm{~cm}$, the results are not generalisable to all patients with early-stage disease. The study by Wu et al had unequal follow-up between study arms. $^{1{ }^{3}}$ The study by Izbicki et $a l^{2}$ had significantly more patients with squamous cell carcinoma in the lymph node sampling group $(53 \%)$ than in the CMLD group $(32 \%$ $\mathrm{p}=0.03)$. Finally, two of the three studies were unblinded during follow-up. ${ }^{1}{ }^{4}$ Even if a small survival benefit exists, this must be weighed against the substantially higher morbidity for patients undergoing CMLD reported in two of the three included studies. ${ }^{24}$ The results of the ACOSOG $\mathrm{Z30}$ trial should help address these trade-offs.
J-E C Holty

Center for Primary Care and Outcomes Research, Stanford, University, Stanford, California, USA

M K Gould

VA Palo Alto Health Care System, Palo Alto, California USA; Stanford University Medical Center, Palo Alto, California, USA; Center for Primary Care and Outcomes Research, Stanford University, Stanford, California,

USA

Correspondence to: $\mathrm{Dr}$ J-E C Holty, Division of Pulmonary and Critical Care Medicine, University School of Medicine, 300 Pasteur Drive, H3143, Stanford, CA 94305-5236, USA; jholty@stanford.edu

Competing interests: None declared.

\section{References}

1 Wu YL, Huang ZF, Wang SY, et al. A randomized trial of systematic nodal dissection in resectable non-small cell lung cancer. Lung Cancer 2002;36: 1-6.

2 Izbicki J, Passlick B, Pantel K, et al. Effectiveness of radical systematic mediastinal lymphadenectomy in patients with resectable non-small cell lung cancer: results of a prospective randomized trial. Ann Surg results of a prospective

3 Barnard J, Dunning J, Musleh G, et al. Is there a role for the use of radical lymph node dissection in the surgical management of resectable non-small cell lung cancer? Interact Cardiovasc Thorac Surg 2004;3:294-9

4 Sugi K, Nawata K, Fujita N, et al. Systematic lymph node dissection for clinically diagnosed peripheral non-small-cell lung cancer less than $2 \mathrm{~cm}$ in diameter. World J Surg 1998;22:290-5.

5 Allen MS, Darling GE, Pechet TV, et al. Morbidity and mortality of major pulmonary resections in patients with early-stage lung cancer: initial results of the randomized, prospective ACOSOG Z0030 trial. Ann Thorac Surg 2006;81:1013-20.

\section{CORRECTION}

doi: 10.1136/thx.2006.063271corrl

The authors of the article entitled "Tiotropium for stable chronic obstructive pulmonary disease: a meta-analysis" (Barr RG, Bourbeau J, Camargo CA, et al. Thorax 2006;61:854-62), published in the October issue, have noticed an error in figure 1 . Reference 26 in figure 1 should refer to a paper not in the reference list: Witek TJ Jr, Mahler DA. Minimal important difference of the transition dyspnoea index in a multinational clinical trial. Eur Respir J 2003;21:267-72. Where reference 26 is cited in the text this correctly refers to the paper listed in the reference list. 